\title{
Combination of SWOT Analysis, Analytic Hierarchy Process, and Monte Carlo Simulation to Identify the Strategic Positioning of Crisis Management at the Ferdowsi University of Mashhad, Iran
}

\author{
Samira Ebrahimifar ${ }^{1} \mathbb{1}$, Zahra Naji-Azimi ${ }^{2} \oplus$, Fariborz Rahimnia ${ }^{2} \mathbb{D}$
}

Date of submission: 20 Feb. 2020 Date of acceptance: 22 Aug. 2020

\begin{abstract}
INTRODUCTION: Iran has long been recognized as one of the most accident-prone areas in the world due to its special geographical location. Therefore, it is of utmost importance to devote special attention to crisis management in organizations and the identification of related strengths, weaknesses, opportunities, and threats.

METHODS: The present study aimed to identify the strategic positioning of crisis management after natural disasters at the Ferdowsi University of Mashhad as the center of excellence in the east of the country. To this end, the internal and external factors which militate against university crisis management were identified. Thereafter, the strategic positioning of this university was determined among four positions, namely offensive, defensive, adaptive, and contingency, using a combination of SWOT (strengths, weaknesses, opportunities, and threats) analysis, analytic hierarchy process (AHP), and Monte Carlo simulation, and strategies were presented. The statistical population were university facility experts and managers among whom 10 cases were selected by purposive sampling.

FINDINGS: Based on the obtained results, the highest weights in different sub-criteria were as follows: compliance with the required technical and safety standards in new constructions of the university campus (strength), the absence of any specific plan for dealing with various types of crises in different buildings (weakness), the proximity of the fire station to the university campus (opportunity), and indecisiveness of organizations supervising building retrofitting, including provincial government and Roads and Urban Development Office (threat).

CONCLUSION: The results of the present study demonstrated that strategic positioning can be identified by analyzing internal and external factors. Moreover, among the four strategic positions, it was found that the Ferdowsi University of Mashhad adopted an offensive crisis management strategy in $45.4 \%$ of the cases.
\end{abstract}

Original Article

Keywords: Crisis Management; Hierarchical Analysis Process; Monte Carlo Simulation; Strategic Positioning Identification; SWOT Matrix.

How to cite this article: Ebrahimifar S, Naji-Azimi Z, Rahimnia F. Combination of SWOT Analysis, Analytic Hierarchy Process, and Monte Carlo Simulation to Identify the Strategic Positioning of Crisis Management at the Ferdowsi University of Mashhad, Iran. Sci J Rescue Relief 2020; 12(2): 93-101.

\section{Introduction}

$\mathrm{T}$ he recent political, economic, social, human, and geographical events have pointed to the exposure and vulnerability of human societies to natural and man-made disasters that can lead to a myriad of crises. In general, organizations and communities are intertwined with crises, and every organization comes under the influence of a variety of crises every single day. Therefore, managers should be always prepared to face crises and take the

1-MA student, Industrial Management, Ferdowsi University of Mashhad, Mashhad, Iran

2-PhD, Faculty Member, Department of Management, Faculty of Economics and Administrative Sciences, Ferdowsi University of Mashhad, Mashhad, Iran

Correspondence to: Zahra Naji-Azimi, Email: znajiazimi@um.ac.ir 
necessary measures to prevent or reduce the destructive effect of crises on their organizations (1).

Today, crisis management as one of the basic missions of organizations is indispensable for the stability and survival of organizations (2). The destructive effect of disasters differs according to geographical conditions. Therefore, it is necessary to be fully aware of the strengths, weaknesses, opportunities, and threats of crisis management in order to reduce the inflicted damage to the environment and achieve the organizational goals in the crisis management process. This knowledge allows us to perform comprehensive planning for the present and future activities of the organization and also plays a peculiar role in the success of crisis management (3).

Crisis management is a critical issue addressed in various settings, including universities. Universities play the most substantial role in the cultural, economic, social, and political development of every country. Therefore, stability and order in higher education bring about longlasting stability and social order, while instability causes social instability. The recent crises in universities pointed to inadequate knowledge of officials regarding the type of crises and instabilities, their cause, and how to manage them properly in universities (4).

Considering the multiplicity of possible crises and the importance of crisis management in universities, especially Ferdowsi University of Mashhad as the center of excellence in the east of the country, the current study aimed to identify the strategic positioning of crisis management after natural disasters at the Ferdowsi University of Mashhad. The current research aimed to determine the strategic positioning of crisis management in this university among four positions, namely defensive, contingency, offensive, and adaptive, using a combination of SWOT (Strengths, Weaknesses, Opportunities, and Threats) analysis, analytic hierarchy process (AHP), and Monte Carlo simulation.

In this combined method, the identified weaknesses, strengths, threats, and opportunities are weighed using AHP methods and Monte Carlo simulations. Thereafter, using the weights and ranks of the factors obtained from the previous stage, the SWOT evaluation matrix is formed, and the strategic positioning of Ferdowsi University is determined among the four positions of adaptive, offensive, defensive, and contingency. Finally, some strategies were presented to take advantage of strengths and opportunities to reduce and eliminate weaknesses and threats.

The specific goals of the current study were as follows: the recognition of the factors and the areas of strength, weakness, opportunity, and threat in crisis management at the Ferdowsi University of Mashhad, the identification of strategic positioning of crisis management at the Ferdowsi University of Mashhad, and developing appropriate strategies at the task level for crisis management in this university. One of the significant innovations developed in the current research was the use of an integrated method of SWOT, AHP, and Monte Carlo simulation, which has not been performed in previous studies. Moreover, another notable innovation was the identification of strategic positioning of crisis management in a university for the first time.

\section{Literature review}

Karimlou (2006) conducted a study to identify the preliminary stages of developing a plan for disaster risk reduction in universities. Moreover, after an overview of different types of organizational systems, it provided a suitable organizational system for earthquake risk management at the University of Tehran (5). Fallah (2010) carried out a study entitled "Earthquake risk reduction in higher education centers at a low cost, case study of Shahid Beheshti University School of architecture and urban development ".

The mentioned study first of all identified the organizational vulnerabilities and then offered risk reduction solutions in organizational and nonorganizational dimensions (6). Along the same lines, Bashiri and Khajehei (2013) carried out a study entitled "Seismic vulnerability reduction and fire risk mitigation in dormitories". They first identified the organizational and non-structural vulnerabilities in dormitories of Shahid Beheshti University. Thereafter, based on observations, questionnaires, and interviews, they examined the incident command system (7)

There is a paucity of studies on the use of SWOT in crisis management in Iran. Chalook (2010) analyzed the current security status in Tehran and presented a policing strategy in confrontation with the earthquake crisis using the SWOT technique (8). Nonetheless, crisis management in non-educational institutions and various industries has received tremendous 
attention, and various articles have been presented in this field.

In their study, Taghvaei and Ghafari (2006) prioritized crises in rural settlements of Bazoft district using the AHP method. Finally, rural areas were categorized into three groups: stable, semistable, and unstable according to the strengths and weaknesses of each crisis in various natural, economic, and social dimensions (9). In the same direction, in their study, Farajzadeh et al. (2010) assessed urban housing vulnerability to the earthquake in District 9 of Tehran municipality. They used the Fuzzy TOPSIS model, GIS software, and some criteria, namely building materials, age of the building, the number of floors, construction quality, population density, and adaptability of land uses (10).

Azizpour et al. (2011) performed a study entitled "Prioritizing the effective factors in urban crisis management against the natural disasters". In this study, they investigated necessary management principles to reduce the vulnerability of cities and prioritize effective factors in urban crisis management in crisis-related organizations in Isfahan (11). In their study, Mastaneh et al. (2011) examined the capabilities and limitations of crisis management in hospitals affiliated to Hormozgan University of Medical Sciences (12).

In Iran, several studies have been conducted on the use of SWOT analysis and its combination with other methods, including multi-criteria decision-making methods. For instance, Nazemi et al. (2009) used the combined model of fuzzy AHP and SWOT analysis in strategic planning of higher education to investigate the internal environment (strengths and weaknesses) and external environment (opportunities and threats) of the Faculty of Economic and Administrative Sciences, Ferdowsi University of Mashhad (13).

Sehat and Prizadi (2009) used SWOT analysis and network analysis process to assess the strategies of Iran Insurance Company, a medical and cosmetic products company, and Arak Petrochemical Company (14). Khorshid and Ranjbar (2010) studied the strategic analysis of an automatic lighting company using SWOT analysis, fuzzy analysis network process, and fuzzy TOPSIS technique. The network designed in the studies conducted by these researchers was similar to the research performed by Sehat and Pirzadi. In this research, after obtaining the weights of strategic factors through the network analysis process, the fuzzy TOPSIS technique was applied to prioritize strategies.

In their research, Mirzaei et al. identified the types of strategies in milk production companies using SWOT analysis and determined the priority of strategies using the group fuzzy AHP method. Sehat et al. formulated and evaluated the strategies adopted by Science and Technology Park using SWOT analysis, fuzzy ANP, and fuzzy DEMATEL. They used the fuzzy group decision technique to determine the internal dependencies of SWOT factors in the network analysis technique (15).

Bozorgkhoo and Afshari (2012) analyzed the strategic human resource management model in Iran Merinos using the fuzzy network analysis technique and SWOT (16). Ranjbarian et al. (2012) analyzed the strengths, weaknesses, opportunities, and threats of the outbound tourism industry in Isfahan using fuzzy AHP (17). Hajinejad and Yari (2012) developed an ecotourism strategic planning for the forest park of Boluran, Kouhdasht using SWOT and TOPSIS models (18).

A few studies have been conducted on the application of the combined method of AHP and Monte Carlo simulation in the country. For instance, Lotfalipour et al. (2013) located the branches of Bank Pasargad in Mashhad using this combined method. In order to prioritize and select the appropriate location for the new branch, they identified the factors influencing the locating of the branches with the help of experts and literature review. Thereafter, they obtained their relative weight by the combined method of the AHP and Monte Carlo simulation (19).

In a master thesis, Karizouni (2013) used a combined method of AHP, Monte Carlo simulation, and Promethee technique to prioritize cities and select the appropriate market for Mashhad Housing Company (20). In their article, Tan et al. (2007) examined an infectious disease crisis in the National University of Singapore using crisis management simulation (21). In another study, Wang et al. (2010) focused on the Virginia Tech shooting in 2007 shooting and examined crisis management in higher education institutions using the Crisis Management Model developed by Mitroff (22).

In a study, Aisha and Jasper (2013) identified the current and future challenges faced by faculty leaders in an Australian university, analyzed the associated risk factors, and developed practical ways to address key challenges (23). Nonetheless, 
the issue of crisis management in various noneducational institutions and industries has received assiduous attention, and multiple articles have been presented in this field, some of which are mentioned below. Paraskevas and Altina (2013) in a study proposed a three-stage conceptual framework for crisis signal detection consisting of signal scanning, capture, and transmission to the crisis response center (24).

In a study, Yuksel et al. (2007) formulated and prioritized the strategies of a textile company using SWOT analysis and network analysis techniques (25). Seeker and Ozgurler (2012) analyzed the Turkish consumer electronics firm using AHP and SWOT (26). Moreover, in the same year, Gorener et al. used the combined method of SWOT and AHP to analyze a manufacturing firm to improve the quantitative aspect of strategic planning (27). Along the same lines, Bas (2013) provided an integrated framework for analysis of the electricity supply chain in Turkey using an integrated SWOT-Fuzzy TOPSIS methodology combined with AHP (28).

Very few research efforts have been made abroad on the application of the combined method of AHP and Monte Carlo simulation. In a study entitled" Modified analytic hierarchy process to incorporate uncertainty and managerial aspects, Banuelas and Antony (2004) used a combination of AHP and Monte Carlo simulation to select the most appropriate technology for new home appliances platforms (29). Hsu and Pan (2009) used simple AHP and then a combination of hierarchical analysis and Monte Carlo simulation to rank dental clinics and finally compared the results (30).

\section{Methods}

This case study was conducted based on an applied research method. The decision team of this research consisted of the managers and experts in natural and technological crises at the Ferdowsi University of Mashhad. To collect the data, 10 experts were interviewed and completed a questionnaire. In the current research, the combined method of SWOT, AHAP, and Monte Carlo simulation was used to determine the strategic positioning of university-related crisis management.

One of the major weaknesses of SWOT analysis lies in the fact that it does not quantify the importance of each factor in decision-making.
Therefore, in the present research, the AHP method was used to resolve the mentioned problem. However, classical AHP came under serious criticism for disregarding uncertainties; therefore, a combination of AHP and Monte Carlo simulation was used in the current study to tackle this problem. In so doing, in AHP pairwise comparisons, instead of considering only one value, three values are regarded as the lowest possible value, the most probable, and the highest possible value. These three values are considered the parameters of the triangular distribution of relevant importance.

The simulation initiates after extracting the internal factor evaluation matrix and the external factor evaluation matrix. In fact, in each simulation, one of the numbers related to the triangular distribution of each pairwise comparison is randomly selected and the AHP process is typically used. After obtaining the weight of factors and combining them in the SWOT technique, the simulation is performed again, and the simulation process is repeated 1000 times.

\section{Findings}

In the present study, in the first stage, the internal factors (strengths and weaknesses) and external factors (opportunities and threats) of crisis management at the Ferdowsi University of Mashhad were identified by literature review and expert interviews. At this stage, the indicators related to strengths, weaknesses, opportunities, and threats were identified by designing a questionnaire and consulting the decision-making team after removing and adding a number of proposed factors and modifying them. They were categorized into six strengths, six weaknesses, four opportunities, and three threats as presented below (Table 1):

\section{Factor weighting}

After identifying the strengths, weaknesses, opportunities, and threats, the integrated method of SWOT, AHP, and Monte Carlo simulation was performed using MATLAB 2013 with 1000 repetitions. Table 2 displays the average weight of the strength sub-criteria in these repetitions. As illustrated in this table, the $\mathrm{S} 1 \mathrm{sub}$-criterion (i.e., the observance of the technical and safety standards required for new constructions in the university campus, has the highest weight in 1000 repetitions. The S5 sub-criterion (i.e., a suitable 
open and free space for crisis control and operation has the least weight and importance.

Table 3 presents the average weight of the weakness sub-criteria in 1000 repetitions. As demonstrated in Table 3, W6 (i.e., lack of a specific crisis response plan for various types of crises in different buildings) has the highest weight. On the other hand, W2 sub-criteria (i.e., low level of firefighting and fire protection standards) has the lowest weight.

In a similar vein, Table 4 shows the average weight of opportunity sub-criteria. As depicted in Table 4, the $\mathrm{O} 2$ sub-criterion (i.e., adjacency to the fire station), has the highest weight, while $\mathrm{O} 4$ (i.e., the proximity of Farabi Hospital to the university campus) has the lowest weight.

Finally, Table 5 shows the average weight of the threat sub-criteria. As presented in this table, T3 (i.e., the indecisiveness of organizations supervising building retrofitting, including provincial government and Roads and Urban Development office), T1 (i.e., lack of sufficient and specific resources allocated by the Ministry of Roads and Urban Development for building retrofitting and crisis management), and T2 (i.e., the inappropriate structure of water channel outside the university) are given the highest weight and importance, respectively.

Table 1. Strengths, weaknesses, opportunities, and threats of Crisis Management in Ferdowsi University of Mashhad

\begin{tabular}{|c|c|c|}
\hline Weaknesses & Strengths & \\
\hline $\begin{array}{l}\text { W1: Lack of strict observance of technical and safety } \\
\text { standards in buildings and facilities in the university } \\
\text { W2: Low level of firefighting and fire safety standards } \\
\text { W3: Absence of proper warning systems to prevent } \\
\text { hazards, such as earthquake warning sensor and } \\
\text { automatic gas shut-off valve } \\
\text { W4: Lack of comprehensive information regarding } \\
\text { infrastructure facilities, including water, gas, and } \\
\text { electricity, in the university } \\
\text { W5: Lack of specialized manpower in the technical and } \\
\text { maintenance sector } \\
\text { W6: Lack of specific crisis management plan for all } \\
\text { types of crises in buildings }\end{array}$ & $\begin{array}{l}\text { S1: Observance of the required technical and } \\
\text { safety standards in new constructions of the } \\
\text { university campus } \\
\text { S2: Existence of health center and ambulance } \\
\text { service inside the university } \\
\text { S3: Continuous identification and analysis of } \\
\text { problems of university buildings and facilities } \\
\text { S4: Performing routine maintenance of } \\
\text { existing university buildings and facilities } \\
\text { S5: Abundance of open space to control } \\
\text { crises and perform the required operations } \\
\text { S6: Convenient and accessible transportation } \\
\text { and communication routes }\end{array}$ & $\begin{array}{l}\text { Internal } \\
\text { factors }\end{array}$ \\
\hline Threats & Opportunities & \\
\hline $\begin{array}{l}\text { T1: Absence of budget allocation and resource planning } \\
\text { for crisis management and building retrofitting } \\
\text { T2: Improper structure of water channels outside the } \\
\text { university } \\
\text { T3: Indecisiveness of organizations supervising building } \\
\text { retrofitting, such as the municipality }\end{array}$ & $\begin{array}{l}\text { O1: Government credit and financial support } \\
\text { for building retrofitting } \\
\text { O2: Proximity to a fire station } \\
\text { O3: Access to the main roads of the city for } \\
\text { relief and disaster control } \\
\text { O4: Adjacency of Farabi Hospital to the } \\
\text { university }\end{array}$ & $\begin{array}{c}\text { External } \\
\text { factors }\end{array}$ \\
\hline
\end{tabular}

Table 2. Average weight of strength sub-criteria

$\begin{array}{ccc}\begin{array}{c}\text { Sub- } \\ \text { criterion }\end{array} & \text { Strengths } & \begin{array}{c}\text { Average in } \\ \text { 1000 repetitions }\end{array} \\ \text { S1 } & \text { Observance of the required technical and safety standards in new constructions of } & 0.26 \\ \text { S2 } & \text { Existence of health center and ambulance service inside the university } & 0.11 \\ \text { S3 } & \text { Continuous identification and analysis of problems of university buildings and facilities } & 0.25 \\ \text { S4 } & \text { Performing routine maintenance of existing university buildings and facilities } & 0.13 \\ \text { S5 } & \text { The abundance of open space to control crises and perform the required operations } & 0.06 \\ \text { S6 } & \text { Convenient and accessible transportation and communication routes } & 0.20\end{array}$

Identification of strategic situation of crisis Mashhad, the strategic situation of this university

\section{management}

Now, based on the final scores obtained from external and internal factor evaluation matrixes of crisis management at the Ferdowsi University of is determined among the four positions of offensive, adaptive, contingency, and defensive. For this purpose, the weighted total scores of the internal factor matrix and the external factor 
matrix are extracted and plotted in the internalexternal (IE) matrix. According to 1000 repetitions of this process, the strategic situation of university-related crisis management was as follows: adaptive( $31.5 \%$ ). 45.4\% ( offensive), $15.8 \%$ (contingency), and $7.3 \%$ (defensive).

\section{Development of strategies at the task level}

To formulate strategies, strengths, and weaknesses, as well as opportunities and threats, are linked in the general framework (SO, WO, ST, WT) (Table 7).

SO offensive strategies: The strategy of creating crisis control infrastructure in the university can be expressed considering the strengths of crisis management at Ferdowsi University and the opportunities that exist outside the university. These infrastructures and facilities can be a helicopter runway and a fire station inside the university since the university campus is abundant in open space and transportation routes. Moreover, the university is financially supported by the government, and the location of Ferdowsi University provides access to the main roads for seeking relief.

Therefore, apart from the people who are inside the campus, the university can provide assistance and help to those outside. This strategy is also in line with the macro strategy of improving the campus physical master plan. Moreover, we can refer to the strategy of interaction with health centers at the time of crisis

Table 3. Average weight of weakness sub-criteria

\begin{tabular}{ccc}
$\begin{array}{c}\text { Sub- } \\
\text { criterion }\end{array}$ & Weaknesses & $\begin{array}{c}\text { Average in 1000 } \\
\text { repetitions }\end{array}$ \\
W1 & $\begin{array}{r}\text { Lack of strict observance of technical and safety standards in buildings and } \\
\text { facilities in the university }\end{array}$ & 0.13 \\
W2 & Low level of firefighting and fire safety standards & 0.09 \\
W3 & Absence of proper warning systems to prevent hazards, such as earthquake & 0.10 \\
warning sensor and automatic gas shut-off valve & 0.21 \\
W5 & Lack of comprehensive information regarding infrastructure facilities, including & 0.15 \\
W6 & Lack of specific crisis management plan for all types of crises in buildings & 0.32 \\
\hline
\end{tabular}

Table 4. Average weight of opportunity sub-criteria

\begin{tabular}{ccc} 
Sub-criterion & Opportunity & Average in 1000 repetitions \\
O1 & Government credit and financial support for building retrofitting & 0.29 \\
O2 & Proximity to a fire station & 0.27 \\
O3 & Access to the main roads of the city for relief and disaster control & 0.24 \\
O4 & The adjacency of Farabi Hospital to the university & 0.20 \\
\hline
\end{tabular}

Table 5. Average weight of threat sub-criteria 
Table 6. Percentage of four situations of crisis management at Ferdowsi University of Mashhad

\section{Position}

Percentage

Offensive

Adaptive

Contingency

15.8

Defensive considering the proximity of the university to Farabi Hospital and the availability of ambulance and health center inside the university. In addition, the strategy of retrofitting of existing university buildings can be indicated regarding the government credit and financial support for building retrofitting, the observance of technical

Table 7. Matrix of Crisis Management Strategies of Ferdowsi University of Mashhad

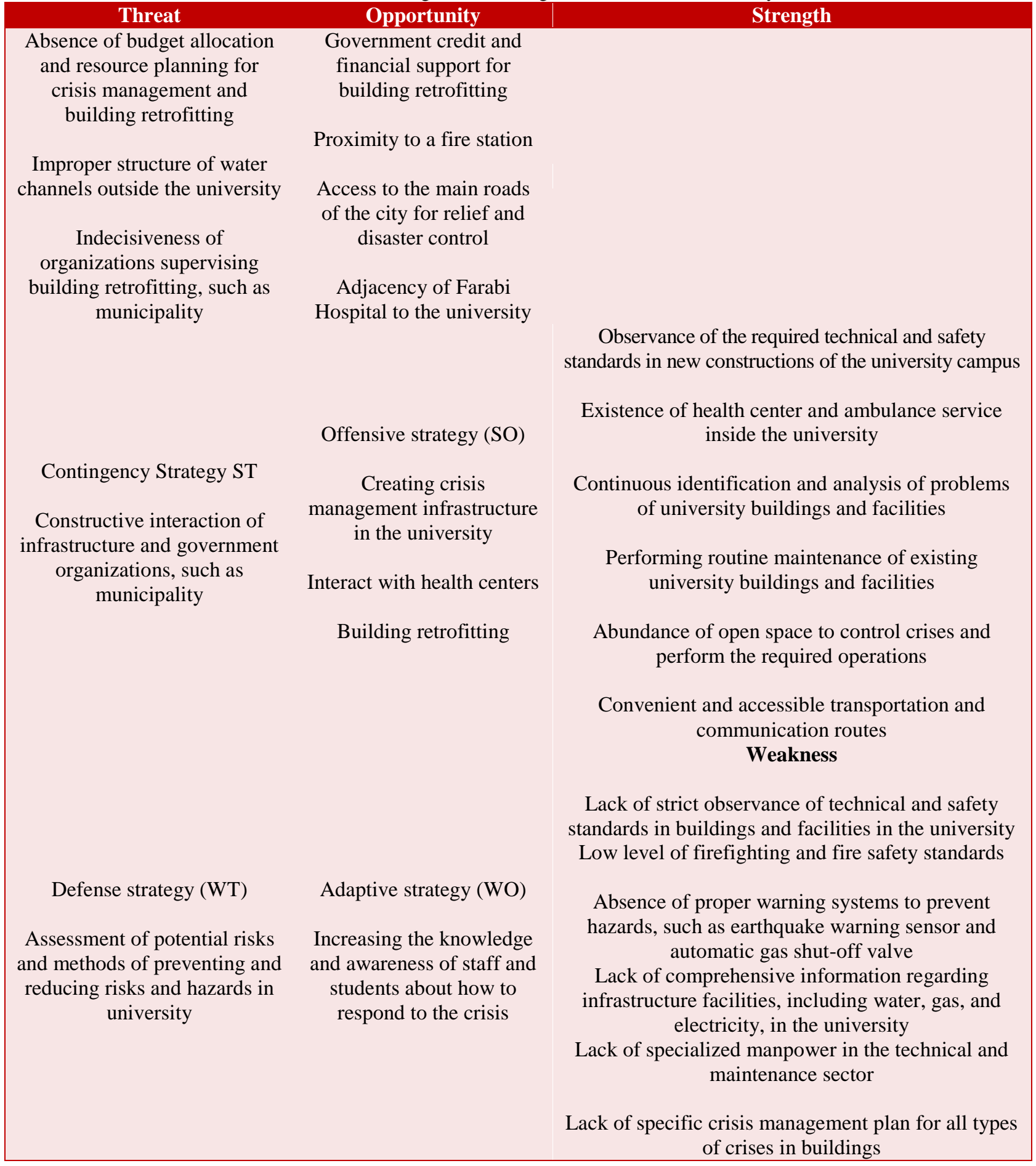


and safety standards in new constructions, and routine maintenance of university buildings and facilities.

Contingency strategy ST: In this part, the strategy of constructive interaction of infrastructure with government organizations, such as the municipality, can be presented given the strength of continuous analysis of problems and shortcomings of the university, as well as the threat of improper structure of the water channel.

Adaptive strategy WO: Technical and safety standards are not observed in buildings and facilities, the level of firefighting standards is low, and a fire station is adjacent to the university campus. Therefore, the following strategy is indicated: "increasing the knowledge and awareness of staff and students regarding crisis confrontation ".

Defense strategy WT: The weaknesses of crisis management in the university and the absence of budget allocation and resource planning by the Ministry indicate the following strategy: "assessing potential risks and methods of preventing and reducing the risk of hazards and disasters".

\section{Discussion and Conclusion}

Identifying strategic positioning is possible by analyzing internal and external factors. The existence of 12 internal factors against 7 external factors points to the advantages and disadvantages of crisis management at the Ferdowsi University of Mashhad. The assessment of the internal and external factors indicated that the most important strength is the observance of the required technical and safety standards in the new constructions of the university campus. Moreover, government credit and financial support for building retrofitting was the most important opportunity.

In addition, the most important weakness was the absence of a clear plan for dealing with various types of crises in different buildings. Finally, the most important threat is the indecisiveness of organizations supervising building retrofitting. The weights obtained for internal and external factors show that some of these factors are more important than others. Therefore, it is suggested that the Ferdowsi University of Mashhad devote more attention to these factors to improve crisis management.

It is also recommended that Ferdowsi
University officials have a crisis management center or at least a comprehensive plan for dealing with crises within the campus of the university. On the other hand, the university can hold pilot maneuvers to assess its Crisispreparedness. Finally, based on the developed strategies, Ferdowsi University of Mashhad will implement operational plans to prepare for crisis management.

In the current research, a combination of AHP and Monte Carlo simulation was used to calculate the weight of strengths, weaknesses, opportunities, and threats. For future research, it is suggested to use a combination of other multicriteria decision-making methods, such as TOPSIS, simple linear weighting, analytic network process (ANP), and simulation methods, to calculate the weight of SWOT factors and compare the results of studies if possible. Moreover, the current study only considered natural and technical crises of the university due to the absence of information.

Therefore, it is recommended that other crises, such as social and political crises, be taken into account in future studies. Furthermore, it is suggested that the crisis-preparedness of the Ferdowsi University of Mashhad be assessed in the future. Finally, it is recommended that the proposed model be implemented in other universities in the country to increase their readiness and identify their strengths, weaknesses, opportunities, and threats.

\section{Acknowledgments}

The authors would like to express their gratitude to all those who contributed to the conduction of this research project.

\section{Conflict of Interests}

Authors have no conflict of interests.

\section{References}

1. Berg T, Zolfaghari M. Crisis management. Tehran: Hadis Press, 1994. [In Persian].

2. Memarzadeh GH, Sarafrazi M. Reviewing the crisis management process steps in the organization. Cultural Soc Res 2010; 51: 9-76. [In Persian].

3. Rezaei MR, Hosseini SM, Hakimi H. Strategic planning for crisis management in Yazd's historical tissue by using SWOT. Emerg Manag 2012; 1(1): 35-44. [In Persian].

4. Rabiee A, Rezghi SH. Crisis management in 
Islamic Azad University. J Crisis Cultural Manag 2011; 4(10): 115-32. [In Persian].

5. Karimlou K. Earthquake risk management plan of Tehran University. [Master Thesis]. Tehran: University of Tehran; 2006. [In Persian].

6. Fallah A. Earthquake risk reduction in higher education centers at a low cost, case study of Shahid Beheshti University School of architecture and urban development. Armanshar 2010; 4(5): 4764. [In Persian].

7. Bashiri M, Khajehei S. Seismic vulnerability reduction and fire risk mitigation in dormitories. Emerg Manag 2013; 2: 13-23. [In Persian].

8. Chalook G. Analysis of current security status in Tehran: offering policing strategy in confrontation with earthquake crisis through using SWOT technique (crisis management). Police Manag Stud 2010; 5(4): 650-76. [In Persian].

9. Taghvaei M, Ghafari SR. Crisis prioritization in rural settlements (AHP method) (case study: Bazoft District). Res Bull Isfahan Univ 2006; 20(1): 47-74. [In Persian].

10. Farajzadeh M, Ahmadinejad M, Amini J. Assessment of urban housing vulnerability to earthquake (case study of district 9 of Tehran municipality). Urban Reg Stud Res 2011; 3(9): 1936. [In Persian].

11. Azizpour M, Zangiabadi A, Esmailian Z. Prioritizing the effective factors in urban crisis management against the natural disasters (studying sample: the organizations related to Isfahan's crisis). Geography Environ Plan 2011; 22(3): 10724. [In Persian].

12. Mastaneh Z, Mouseli L. Capabilities and limitations of crisis management in the teaching hospitals of Hormozgan University of Medical Sciences, 2010. Sci Res Essays 2013; 8(26): 1196202. [In Persian].

13. Nazemi S, Fathi A, Didekhani H. Applying the Combined Model of SWOT and Fuzzy AHP in strategic planning of higher education, case study of the faculty of economics and administrative sciences. Sci Technol 2010; 1(2): 76-96. [In Persian].

14. Sehat S, Parizadi A. Application of network analysis process technique in analysis of strengths, weaknesses, opportunities, threats (case study of Iran insurance company). Indust Manag 2009; 1(2): 105-20. [In Persian].

15. Abouei MH, Razmi SM. Conglomerate diversification strategy. J Strategic Manag Stud 2013; 4(13): 43-68. [In Persian].

16. Bozorgkho H, Afshari M. Strategic HRM model using fuzzy ANP and SWOT. Third Management Conference, Tehran, Iran; 2012. [In Persian].
17. Ranjbarian B, Khazai J, Baloi H. Analysis of outbound tourism industry in Isfahan by fuzzy AHP. Tourism Plan Dev 2013; 1(1): 13-34. [In Persian].

18. Hajinejad A, Yari M. Ecotourism strategic planning "using SWOT and TOPSIS methods" case: forest park of Boluran, Kouhdasht. Geography Dev 2013; 11(32): 177-91. [In Persian].

19. Lotfalipour Z. Location of bank branches using integrated hierarchical analysis and Monte Carlo simulation (case study: Pasargad Bank in Mashhad). [Master Thesis]. Mashhad: Ferdowsi University; 2004. [In Persian].

20. Karizouni A. Applying combined hierarchical analysis method, Monte Carlo simulation, and parametric to prioritize and select appropriate market. [Master Thesis]. Mashhad: Ferdowsi University; 2014. [In Persian].

21. Tan GS, Lau R. Crisis management simulation: Spread of diseases in national university of Singapore. Asian Simulation Conference, Berlin, Germany; 2007. P. 75-84.

22. Wang J, Hutchins HM. Crisis management in higher education: what have we learned from Virginia Tech? Adv Dev Hum Res 2010; 12(5): 552-72.

23. Kamarazaly MA, Mbachu J, Phipps R. Challenges faced by facilities managers in the Australasian universities. J Facil Manag 2013; 11(2): 136-51.

24. Paraskevas A, Altinay L. Signal detection as the first line of defense in tourism crisis management. Tourism Manag 2013; 34: 158-71.

25. Yuksel I, Dagdeviren M. Using the analytic network process (ANP) in a SWOT analysis- a case study for a textile firm. Informat Sci 2007; 177(16): 3364-82.

26. Seker S, Ozgurler M. Analysis of the Turkish consumer electronics firm using SWOT-AHP method. Proc Soc Behav Sci 2012; 58: 1544-54.

27. Gorener A, Toker K, Ulucay K. Application of combined SWOT and AHP: a case study for a manufacturing firm. Proc Soc Behav Sci 2012; 58: 1525-34.

28. Bas E. The integrated framework for analysis of electricity supply chain using an integrated SWOTFuzzy TOPSIS methodology combined with AHP: the case of Turkey. Electrical Power Energy Syst 2013; 44(1): 897-90.

29. Banuelas R, Antony J. Modified analytic hierarchy process to incorporate uncertainty and managerial aspects. Int J Product Res 2004; 42(18): 3851-72.

30. Hsu TH, Pan FF. Application of Monte Carlo AHP in ranking dental quality attributes. Expert Syst Appl 2009; 36(2): 2310-6. 